\title{
Echocardiographic parameters in dogs treated with acepromazine and fentanyl
}

\author{
[Parâmetros ecocardiográficos em cães tratados com acepromazina e fentanil] \\ E.A. Santos ${ }^{1}$, K.P. Aptekmann ${ }^{2}$, P.O.P.R. Santos ${ }^{1}$, A.C. Reis ${ }^{2}$, M.C.C. Kuster ${ }^{1}$, \\ P.S.C. Andrade Junior ${ }^{3}$ \\ ${ }^{1}$ Aluno de pós-graduação - Universidade Federal do Espírito Santo - Alegre, ES \\ ${ }^{2}$ Universidade Federal do Espírito Santo - Alegre, ES \\ ${ }^{3}$ Instituto Federal do Espírito Santo - Alegre, ES
}

\begin{abstract}
Considering that the use of tranquillizers could optimize the performance of the echocardiogram, this study aimed to evaluate the effect of protocols with acepromazine and fentanyl on the echocardiographic parameters of healthy dogs, besides their effect in systolic blood pressure (SBP), respiratory rate (RR), heart rate (HR), time spent for examination and sedation scale. Ten adult dogs were submitted to different tranquilizing protocols 20 minutes before the echocardiographic examination, totalling five treatments for each pair, performed at seven-day intervals between evaluations. The treatments were CT (control treatment), IAT (intramuscular acepromazine), OAT (oral acepromazine), FT (fentanyl) and AFT (acepromazine associated with fentanyl). In addition to the echocardiographic evaluation, SBP, degree of reassurance, duration of the exam, HR and RR in the different protocols were evaluated. There was a significant decrease of SBP in OAT. There was a significant reduction in left ventricular diameter during systole and diastole and mitral annular movement in IAT, OAT and AFT, compared with CT. There was a decrease in tricuspid annular plane systolic excursion and increase in mitral E/mitral A ratio in IAT and OAT when compared with $\mathrm{CT}$. All the tranquillizer protocols studied were found to significantly reduce $\mathrm{HR}$, that facilitated the echocardiographic examination.
\end{abstract}

Keywords: echocardiography, phenothiazine, opioid

\section{RESUMO}

Considerando que o uso de tranquilizantes poderia otimizar a realização do ecocardiograma, objetivouse com este estudo avaliar o efeito da tranquilização com acepromazina e fentanil sobre os parâmetros ecocardiográficos em cães saudáveis, bem como o efeito na pressão arterial sistólica (PAS), na frequência respiratória $(F R)$, na frequência cardíaca $(F C)$, no tempo gasto para a realização do exame e na escala de sedação. Dez cães adultos foram submetidos a diferentes protocolos tranquilizantes, 20 minutos antes da avaliação ecocardiográfica, totalizando cinco tratamentos para cada dupla, realizados com intervalos de sete dias entre as avaliações. Os tratamentos foram: TC (tratamento controle), TAI (acepromazina intramuscular), TAO (acepromazina oral), TF (fentanil) e TAF (acepromazina associada ao fentanil). Além dos parâmetros ecocardiográficos, foram avaliados a PAS, o grau de tranquilização, o tempo de duração do exame e a FC e a FR nos diferentes protocolos. Houve diminuição significativa da PAS no TAO. Observou-se redução significativa do diâmetro do ventrículo esquerdo em sístole e diástole e do movimento anular de mitral nos protocolos TAI, TAO e TAF, comparados com o TC. Observou-se também uma redução da excursão sistólica do plano anular tricúspide e aumento da relação mitral E/mitral A nos protocolos TAI e TAO quando comparados ao TC. Todos os protocolos de tranquilização reduziram significativamente a $\mathrm{FC}$, o que facilitou a realização do exame.

Palavras-chave: ecocardiograma, fenotiazínico, opioide

Recebido em 7 de maio de 2017

Aceito em 5 de março de 2018

*Autor para correspondência (corresponding author)

E-mail: kapreising@gmail.com 


\section{INTRODUCTION}

In the last decades, the echocardiogram has become one of the most important complementary exams in veterinary cardiology (Della Torre et al., 2000). High portability, ability to rapidly form images in real time, wide availability and a non-invasive nature are the main advantages (Ram et al., 2011). This exam allows the identification of anatomical structures, size, function and haemodynamics of the heart and large vessels, helping to detect congenital and acquired heart diseases (Chetboul et al., 2015).

The positioning required to perform the echocardiographic exam is often not tolerated by dogs, which express restlessness, stress, or dyspnoea, impairing the formation of the image and favouring the appearance of artefacts (Boon, 2011; Chetboul et al., 2015). An alternative way to minimize the problems caused by movement of the animal during the exam is the use of tranquilizers, as it promotes better image quality and, depending on the drug used, can decrease the heart rate (HR), which is generally increased in these animals (Muzzi et al., 2009).

Although many tranquilizers are used in animals to perform imaging exams (Hall and Waltrous, 2000), caution should be exercised in the choice of the drug to be used for echocardiogram, with knowledge of the cardiovascular changes that can occur in their use. It is known that drugs that have cardiovascular effects, such as hypotension, hypertension, bradycardia and tachycardia, can directly interfere with echocardiographic parameters. Hypotension and bradycardia can cause a decrease in cardiac output and hypertension makes it difficult for the blood to escape from the left ventricle and may increase afterload and decrease the shortening fraction (SF), as well as the ejection fraction (EF), as a result. In tachycardia, there may be a union of mitral-E with mitral-A, a slight increase in inotropic function and an increase in cardiac output in healthy animals (Boon, 2011).

Opioids and phenothiazines are among the most suitable drugs for echocardiographic examination because they have few cardiovascular effects (Kittleson and Kienle, 1998). Acepromazine (phenothiazine) and fentanyl (opioid) are accessible drugs widely used in veterinary medicine and can be administered parenterally and orally in the case of acepromazine (Spinosa et al., 2011). The acepromazine used alone can cause a decrease in left ventricular diameter in systole (Saponaro et al., 2013) and, associated with methadone or butorphanol, may decrease SF in dogs (Cardoso et al, 2016). However, there are no reports of the effect of this drug administered orally or in combination with fentanyl on echocardiographic parameters in dogs.

Considering that the use of tranquillizers could optimize the performance of the echocardiogram examination, this study aimed to evaluate the effect of protocols with acepromazine and fentanyl on the echocardiographic parameters of healthy dogs, besides their effect in systolic blood pressure (SBP), respiratory rate (RR), HR, time spent for examination and sedations scale.

\section{MATERIAL AND METHODS}

This study was approved by the Committee on Ethics in the Use of Animals (CEUA-UFES) under protocol number $67 / 2015$, according to the ethical principles in animal experimentation standardized by the Brazilian College of Animal Experimentation.

Ten adult Rottweilers were used. They were clinically healthy, five males and five females, aged between 13 and 72 months $(47 \pm 17.74$ months) and weighting from 38 to $55 \mathrm{~kg}$ $(46.53 \pm 4.96 \mathrm{~kg})$. They were from the Rancho Piorra Kennel, located in Marataízes - Espírito Santo. For permission to use the animals, the owner of the kennel was informed about the study and signed the informed consent.

The dogs were selected by performing a general anamnesis and physical examination, as well as electrocardiographic, echocardiographic and SBP measurements. Animals that presented any changes that indicated a cardiovascular disease were excluded from the study.

The animals selected were grouped in pairs at random and distributed in a Latin square design. Each pair was submitted to different reassurance protocols 20 minutes before the echocardiographic evaluation, totalling five treatments for each pair, performed at intervals of seven days between evaluations. The 
treatments were CT (control treatment), IAT (intramuscular acepromazine treatment), FT (fentanyl treatment), AFT (acepromazine and fentanyl treatment) and OAT (oral acepromazine treatment).

The CT consisted of administering $2 \mathrm{ml}$ of $0.9 \%$ sterile saline solution per animal intramuscularly (IM). In the IAT, acepromazine (Aceproven 1\% injectable $\AA$, Acepromazine, Vencofarma, Brazil) was administered at the dose of $0.05 \mathrm{mg} / \mathrm{kg} / \mathrm{animal} / \mathrm{IM}$. Fentanyl citrate (Fentanest ${ }^{\circledR} \quad 0.05 \mathrm{mg} / \mathrm{mL}$, fentanyl citrate, Cristália, Brazil) at the dose of $0.0025 \mathrm{mg} / \mathrm{kg} / \mathrm{animal} / \mathrm{IM}$ was used in the FT. The AFT consisted of the use of acepromazine at the dose of $0.05 \mathrm{mg} / \mathrm{kg} / \mathrm{animal}$, associated with fentanyl at the dose of $0.0025 \mathrm{mg} / \mathrm{kg} / \mathrm{animal} / \mathrm{IM}$. In the OAT, Acepromazine (Acepram gotas ${ }^{\circledR} 1 \%$, Acepromazina, Vetnil, Brazil) at the dose of $0.5 \mathrm{mg} / \mathrm{kg} / \mathrm{animal}$ was administered orally. For the application of the drugs, the dogs were physically contained.

The SBP was determined by a non-invasive method with vascular ultrasound Doppler (Vascular Doppler type Pastille, Medmega, Brazil) before (M0) and after 20 minutes of drug administration (M20). It was used as a complementary exam in the interpretation of echocardiographic parameters.

The echocardiographic examination was performed by the same operator using portable ultrasonographic equipment (Esaote MylabTM 30 Vet Gold, Brazil) with a sectoral transducer PA240 at the frequency of 1 to $4 \mathrm{MHz}$. The animals were placed in the right and left lateral decubitus positions, and echocardiographic measurements were performed according to the descriptions in the literature (Schober and Fuentes, 2001; Boon, 2011; Pariaut et al., 2012). In the right parasternal window, on the transverse axis, the following parameters were evaluated in $\mathrm{M}$ mode: diastolic and systolic interventricular septum thickness (IVSd and IVSs), diastolic and systolic left ventricular diameter (LVDd and LVDs), left ventricular free wall in diastole (LVFWd) and systole (LVFWs) and distance from the septum to point E (E-septum) of the mitral valve. From the measurements performed in $\mathrm{M}$ mode, the ejection fraction (EF) was calculated by using Teichholz's method; and the SF was obtained by measuring the left ventricular end-diastolic dimension and left ventricular end-systolic dimension, dividing the difference by the left ventricular end-diastolic dimension. In mode $\mathrm{B}$, the left atrial (LA) and aorta (Ao) diameter were determined, and their relation (LA/Ao) was calculated. In the cardiac base image, spectral Doppler evaluation of the maximum pulmonary flow velocity (Ap-Vmax) and color Doppler of the pulmonary artery were performed.

In the left parasternal window in the apical image, the spectral Doppler values were obtained for the mitral flow - wave A (mitral A) and wave $\mathrm{E}$ (mitral E), maximal aortic flow velocity (AoVmax), isovolumetric relaxation time (TRIV), and Doppler evaluation in colour of the mitral, aorta and tricuspid. In $\mathrm{M}$ mode, the values of mitral annular movement (MAM) and tricuspid annular plane systolic excursion (TAPSE) were obtained.

The ease of performing the echocardiographic exam was determined blindly, by the same evaluator, by means of the total time taken to perform the echocardiographic exam in minutes ( $\mathrm{min}), \mathrm{HR}$ in beats per minute $(\mathrm{bpm}), \mathrm{RR}$ in movements per minute (mpm), besides the degree of sedation of the animals in the different treatments. The time counting was started using a digital timer from the time the animal was placed in the lateral decubitus position to perform the examination. HR was determined from thoracic auscultation using a stethoscope and RR by counting thoracic movements at both M0 and M20. The degree of tranquilization was assessed 20 minutes after the drug application using a descriptive sedation score developed by Gurney et al. (2009), which gives a general score of 0 to $15(0=$ no sedation, $15=$ deep sedation $)($ Table 1$)$.

A statistical analysis was performed using a computerised statistical program (BioEstat, version 5.3, Brasil). Results from echocardiographic parameters, SBP, HR, RR, sedation scale and time of examination were compared between different treatments (CT, IAT, FT, AFT and OAT) in M20; and SBP, HR and RR were also compared between different moments (M0 and M20). The results were presented as mean \pm standard deviation (SD). The D'Agostino test was used to test the normality of the data obtained. The analysis of variance (ANOVA) followed by Tukey test was 
applied to SBP, echocardiographic parameters, HR and RR; and Kruskal-Wallis test followed by Dunn test was used for the total time taken to perform the echocardiographic exam and the sedation scale. Significance was set a $\mathrm{P}<0.05$ in all cases. A descriptive analysis was performed for color Doppler.

Table 1. Simple descriptive sedation score. A score of 0 indicates the absence of sedation and 15 indicates deep sedation (Adapted from Gurney et al., 2009)

\begin{tabular}{cccc}
\hline Spontaneous posture & \multicolumn{2}{c}{ Eyelid reflex } \\
\hline Standing & 0 & Present & 0 \\
Lateral decubitus & 1 & Decreased & 1 \\
Sternal recumbency & 2 & Absent & 2 \\
Sound response (palms) & & Resistance to lateral decubitus & 0 \\
Body movement & 0 & Complete resistance & 1 \\
Head movement & 1 & Moderate contention required & 2 \\
Ear movement & 2 & Slight contention required & 3 \\
No reaction & 3 & No resistance & 0 \\
Ocular Position & & General appearance & 1 \\
To Front (normal positioning) & 0 & No apparent sedation & 2 \\
Ventrally rotated & 2 & Mild sedation & 3 \\
\hline
\end{tabular}

\section{RESULTS AND DISCUSSION}

The mean values of SBP obtained at M0 and M20 are shown in Table 2. There was not a significant difference between the treatments and CT, when comparing SBP values in M20. Although, the SPB values were significantly lower in OAT than IAT and AFT. Only in OAT was a significant decrease of SBP observed between the two moments evaluated. The decrease in SBP observed in OAT is in accordance with the observations of other authors who also used this drug at the same dose as used in this study $(0.05 \mathrm{mg} / \mathrm{kg}$ ) (Gonçalves et al., 2009; Grasso et al. 2015) and occurs through the blockade of $\alpha$-adrenergic vasoconstriction mediated by this drug (Arena et al., 2009).
The mean values and standard deviation of the echocardiographic parameters evaluated in the different treatments are described in Table 3. None of the dogs evaluated presented changes in color Doppler.

There was a significant reduction of LVDd and LVDs in the IAT, AFT and OAT protocols compared to those in the CT. The reduction of ventricular diameter observed in OAT protocol is explained by the decrease in the preload as a consequence of SBP reduction after the use of acepromazine, as reported in the literature (Saponaro et al., 2013). The reduction in LVDd and LVDs observed in the other protocols can only be explained by the hypotension caused by acepromazine, that was not so important to decrease the SBP value, but sufficient to decrease the volume in left ventricle.

Table 2. Mean and standard deviation of systemic systolic blood pressure (SBP) obtained in Rottweilers $(n=10)$ before (M0) and after (M20) tranquilization with acepromazine, fentanyl, or acepromazine associated with fentanyl or oral acepromazine

\begin{tabular}{ccc} 
Treatment & M0 & M20 \\
\hline CT & $124.5^{\mathrm{a}} \pm 30.5$ & $123.0^{\mathrm{aA}} \pm 17.7$ \\
FT & $127.6^{\mathrm{a}} \pm 17.8$ & $128.5^{\mathrm{aA}} \pm 19.3$ \\
IAT & $127.1^{\mathrm{a}} \pm 26.4$ & $106.9^{\mathrm{aAB}} \pm 10.5$ \\
AFT & $136.5^{\mathrm{a}} \pm 16.3$ & $126.5^{\mathrm{aAB}} \pm 24.2$ \\
OAT & $141.5^{\mathrm{a}} \pm 27.2$ & $101.5^{\mathrm{bAC}} \pm 17.0$ \\
\hline
\end{tabular}

The averages followed by the same lower case letters in a line and the same capital letters in a column do not differ statistically from each other by the Tukey test at the 5\% probability level. Subtitle: CT - control treatment; FT fentanyl treatment; IAT - acepromazine treatment; AFT - acepromazine and fentanyl treatment; OAT - oral acepromazine treatment. 
Table 3. Mean and standard deviation of echocardiographic parameters of healthy Rottweiler dogs $(n=$ 10) before and after tranquilization with acepromazine, fentanyl, fentanyl associated acepromazine or oral acepromazine

\begin{tabular}{|c|c|c|c|c|c|c|}
\hline \multirow{2}{*}{ Parameters } & \multicolumn{5}{|c|}{ Treatments } & \multirow[b]{2}{*}{$\mathrm{P}$-value } \\
\hline & $\mathrm{CT}$ & IAT & FT & AFT & OAT & \\
\hline IVSd (mm) & $13.59^{\mathrm{a}} \pm 2.20$ & $15.71^{\mathrm{a}} \pm 2.07$ & $14.49^{\mathrm{a}} \pm 2.42$ & $14.28^{\mathrm{a}} \pm 1.93$ & $14.83^{\mathrm{a}} \pm 3.08$ & ns \\
\hline IVSs (mm) & $17.58^{\mathrm{a}} \pm 1.87$ & $19.78^{\mathrm{a}} \pm 1.82$ & $18.66^{\mathrm{a}} \pm 1.97$ & $18.95^{\mathrm{a}} \pm 2.34$ & $18.89^{\mathrm{a}} \pm 3.22$ & ns \\
\hline LVDd (mm) & $42.98^{\mathrm{a}} \pm 4.47$ & $39.55^{\mathrm{b}} \pm 3.49$ & $42.76^{\mathrm{a}} \pm 4.42$ & $38.87^{\mathrm{b}} \pm 3.34$ & $39.44^{\mathrm{b}} \pm 3.23$ & $\mathrm{P}<0.05$ \\
\hline LVDs (mm) & $28.45^{\mathrm{a}} \pm 2.93$ & $25.41^{\mathrm{b}} \pm 3.52$ & $28.37^{\mathrm{a}} \pm 3.87$ & $25.57^{\mathrm{b}} \pm 4.19$ & $25.30^{\mathrm{b}} \pm 2.97$ & $\mathrm{P}<0.05$ \\
\hline LVFWd (mm) & $13.68^{\mathrm{a}} \pm 1.51$ & $13.67^{\mathrm{a}} \pm 1.14$ & $13.23^{\mathrm{a}} \pm 1.07$ & $13.87^{\mathrm{a}} \pm 1.65$ & $13.73^{\mathrm{a}} \pm 1.79$ & $\mathrm{~ns}$ \\
\hline LVFWs (mm) & $17.30^{\mathrm{a}} \pm 1.92$ & $18.22^{\mathrm{a}} \pm 2.19$ & $17.27^{\mathrm{a}} \pm 1.18$ & $17.92^{\mathrm{a}} \pm 2.59$ & $17.16^{\mathrm{a}} \pm 2.16$ & $\mathrm{~ns}$ \\
\hline Aod (mm) & $24.84^{\mathrm{a}} \pm 3.01$ & $21.77^{\mathrm{a}} \pm 2.84$ & $23.41^{\mathrm{a}} \pm 2.49$ & $23.67^{\mathrm{a}} \pm 2.57$ & $24.41^{\mathrm{a}} \pm 2.82$ & $\mathrm{~ns}$ \\
\hline LAd (mm) & $29.95^{\mathrm{a}} \pm 4.40$ & $27.63^{\mathrm{a}} \pm 2.01$ & $30.70^{\mathrm{a}} \pm 2.15$ & $26.66^{\mathrm{a}} \pm 3.09$ & $30.16^{\mathrm{a}} \pm 4.77$ & ns \\
\hline LA/Ao & $1.21^{\mathrm{a}} \pm 0.17$ & $1.29^{\mathrm{a}} \pm 0.21$ & $1.32^{\mathrm{a}} \pm 0.15$ & $1.14^{\mathrm{a}} \pm 0.19$ & $1.23^{\mathrm{a}} \pm 0.13$ & $\mathrm{~ns}$ \\
\hline $\mathrm{EF}(\%)$ & $62.60^{\mathrm{a}} \pm 4.92$ & $65.9^{\mathrm{a}} \pm 5.62$ & $62.61^{\mathrm{a}} \pm 6.36$ & $63.70^{\mathrm{a}} \pm 9.38$ & $59.81^{\mathrm{a}} \pm 5.61$ & ns \\
\hline Mitral E $(\mathrm{m} / \mathrm{s})$ & $0.84^{\mathrm{a}} \pm 0.13$ & $0.83^{\mathrm{a}} \pm 0.14$ & $0.76^{\mathrm{a}} \pm 0.14$ & $0.82^{\mathrm{a}} \pm 0.14$ & $0.79^{\mathrm{a}} \pm 0.09$ & ns \\
\hline Mitral A $(\mathrm{m} / \mathrm{s})$ & $0.45^{\mathrm{a}} \pm 0.08$ & $0.40^{\mathrm{a}} \pm 0.06$ & $0.41^{\mathrm{a}} \pm 0.06$ & $0.43^{\mathrm{a}} \pm 0.06$ & $0.37^{\mathrm{a}} \pm 0.05$ & ns \\
\hline $\mathrm{E} / \mathrm{A}$ & $1.80^{\mathrm{c}} \pm 0.24$ & $2.1^{\mathrm{ab}} \pm 0.32$ & $1.83^{\mathrm{c}} \pm 0.28$ & $1.92^{\mathrm{bc}} \pm 0.24$ & $2.18^{\mathrm{a}} \pm 0.40$ & $\mathrm{P}<0.05$ \\
\hline Ao-Vmáx (m/s) & $1.31^{\mathrm{a}} \pm 0.18$ & $1.21^{\mathrm{a}} \pm 0.17$ & $1.26^{\mathrm{a}} \pm 0.17$ & $1.26^{\mathrm{a}} \pm 0.15$ & $1.15^{\mathrm{a}} \pm 0.18$ & $\mathrm{~ns}$ \\
\hline Ap-Vmáx (m/s) & $1.33^{\mathrm{a}} \pm 0.14$ & $1.21^{\mathrm{a}} \pm 0.15$ & $1.16^{\mathrm{a}} \pm 0.16$ & $1.21^{\mathrm{a}} \pm 0.28$ & $1.11^{\mathrm{a}} \pm 0.14$ & $\mathrm{~ns}$ \\
\hline TRIV (ms) & $56.40^{\mathrm{a}} \pm 6.4$ & $55.60^{\mathrm{a}} \pm 5.10$ & $53.02^{\mathrm{a}} \pm 5.20$ & $57.81^{\mathrm{a}} \pm 8.24$ & $53.60^{\mathrm{a}} \pm 7.90$ & ns \\
\hline E-septum (mm) & $3.39^{\mathrm{a}} \pm 1.20$ & $2.87^{\mathrm{a}} \pm 1.57$ & $2.85^{\mathrm{a}} \pm 1.49$ & $2.63^{\mathrm{a}} \pm 1.09$ & $3.02^{\mathrm{a}} \pm 1.46$ & ns \\
\hline MAM (mm) & $10.95^{\mathrm{a}} \pm 1.01$ & $6.18^{\mathrm{c}} \pm 1.12$ & $10.30^{\mathrm{a}} \pm 0.78$ & $6.94^{\mathrm{bc}} \pm 1.12$ & $6.09^{c} \pm 1.83$ & $\mathrm{P}<0.05$ \\
\hline TAPSE (mm) & $16.88^{\mathrm{a}} \pm 2.35$ & $13.95^{\mathrm{b}} \pm 2.97$ & $17.13^{\mathrm{a}} \pm 1.40$ & $14.48^{\mathrm{ab}} \pm 1.61$ & $13.43^{\mathrm{b}} \pm 1.39$ & $\mathrm{P}<0.05$ \\
\hline $\mathrm{SF}(\%)$ & $33.60^{\mathrm{a}} \pm 3.62$ & $35.90^{\mathrm{a}} \pm 4.04$ & $33.60^{\mathrm{a}} \pm 4.45$ & $35.43^{\mathrm{a}} \pm 5.12$ & $31.51^{\mathrm{a}} \pm 4.01$ & ns \\
\hline
\end{tabular}

In each line, the averages followed by the same letters do not differ statistically from each other by the Tukey test at the 5\% probability level. Subtitle: CT - control treatment; IAT - acepromazine treatment; FT - fentanyl treatment; AFT - acepromazine and fentanyl treatment; OAT - oral acepromazine treatment; IVSd - interventricular septum in diastole; IVSd - interventricular septum in systole; LVDd - diastolic left ventricular diameter; LVDs - systolic left ventricular diameter; LVFWd - left ventricular free wall in diastole; LVFWd - left ventricular free wall in systole; LAd - left atrium diameter; Aod - aorta diameter; LA/Ao - left atrium/aorta ratio; EF - ejection fraction; Mitral E rapid filling of the left ventricle; Mitral A - slow filling of the left ventricle; E/A - mitral E/mitral A ratio; Vmax-Ao maximal aortic flow velocity, Vmax-Ap - maximal pulmonary artery flow velocity; TRIV - isovolumetric relaxation time; E-septum - distance from the interventricular septum to point E; MAM - mitral annular movement; TAPSE systolic excursion of the annular tricuspid plane; SF - shortening fraction.

A significant increase in mitral E/mitral A ratio was observed in the IAT and the OAT protocols compared to that in the CT. The increase in this relationship occurred due to the decrease in mitral A, which although not significant, may also occur due to the hypotension caused by the use of acepromazine. When there is a decrease in blood volume reaching the heart, the passive passage of blood from the left atrium to the left ventricle (mitral E) remains constant, leaving a smaller volume for the active passage (mitral A), causing a decrease in this parameter (Boon, 2011).

Regarding the echocardiographic parameters used to evaluate cardiac systolic function (MAM, TAPSE and SF) (Boon, 2011), MAM showed a significant decrease in all treatments containing acepromazine, and TAPSE showed a significant reduction in the IAT and the OAT when compared to that in the $\mathrm{CT}$. The reduction of MAM and TAPSE suggest a decrease in longitudinal contractility of the left and right ventricles, respectively. It is known that the alteration of systolic parameters in the echocardiogram can be influenced by preload, afterload or myocardial contractility (Boon, 2011). Thus, the reduction of MAM and TAPSE observed in this study can be attributed to the hypotension caused by acepromazine in the OAT in a way that culminates in a decrease in preload, impairing adequate stretching of the myocardial fibres. As described for LVD, the reduction in MAM at IAT and AFT, and TAPSE at IAT, could be associated to decrease in blood volume caused by acepromazine, although no significant reduction in SBP was observed. There was no significant change in SF after the protocols 
performed; however, SF reduction was already described in the literature after the use of acepromazine due to alpha-adrenergic blockade and consequent peripheral vasodilation (Cardoso et al, 2016).
The mean values and standard deviation of the scores obtained on the sedation scale and the time of examination in the different treatments performed are described in Table 4.

Table 4. Mean and standard deviation of sedation score and time of echocardiographic examination obtained in healthy Rottweilers $(n=10)$ after tranquilization with acepromazine, fentanyl, fentanyl associated acepromazine or oral acepromazine

\begin{tabular}{ccc}
\hline Treatment & Sedation Scale $(\mathrm{pts})$ & Exam Time $(\mathrm{min})$ \\
\hline CT & -- & $18.70^{\mathrm{a}} \pm 9.85$ \\
FT & $2.40^{\mathrm{a}} \pm 1.17$ & $18.40^{\mathrm{a}} \pm 5.37$ \\
IAT & $3.25^{\mathrm{a}} \pm 1.47$ & $15.62^{\mathrm{a}} \pm 4.37$ \\
AFT & $4.50^{\mathrm{ab}} \pm 2.06$ & $15.50^{\mathrm{a}} \pm 4.45$ \\
OAT & $7.80^{\mathrm{b}} \pm 2.04$ & $14.30^{\mathrm{a}} \pm 2.11$ \\
\hline
\end{tabular}

The averages followed by the same letters in a column do not differ statistically from each other by the Dunn Test at the 5\% probability level. Subtitle: CT - control treatment; FT - fentanyl treatment; IAT - acepromazine treatment; AFT - acepromazine and fentanyl treatment; OAT - oral acepromazine treatment; pts - points; min - minutes.

There was not a significant difference in the total time spent performing the echocardiographic exam in all treatments, although it was demonstrated that the sedation protocols made the examination faster. OAT conferred a greater degree of animal reassurance than FT and IAT. Although AFT was expected to have a superior sedation scale due to the effect of neuroleptoanalgesia conferred by the drug association (Hofmeister et al., 2010), this protocol not differed from the others.

The mean and standard deviation of the heart and respiratory rate values obtained in the different treatments performed are described in Table 5 . No significant difference was observed in HR between treatments in M20. All the tranquillizer protocols studied were found to significantly reduce $\mathrm{HR}$ from M0 to M20. Although the literature reports reflex tachycardia as a consequence of hypotension caused by acepromazine (Spinosa et al., 2011), it was observed that acepromazine used in isolation or associated with fentanyl caused a decrease in this parameter. This change has already been described previously (Gonçalves et al., 2009) and may be associated with the ability of this drug to cause vagal-mediated sinus bradycardia (Arena et al., 2009). Although fentanyl caused bradycardia in this study, it is known that it does not produce significant changes in cardiac output (Spinosa et al., 2011). Decreased HR allowed better alignment of the $M$ mode for the echocardiographic measurements, and associated with the reduction of voluntary movements of the animals caused by the reassurance, facilitated the examination.

Table 5. Mean and standard deviation of heart rate (bpm) and respiratory rate (mpm) obtained in Rottweilers $(n=10)$ before (M0) and after (M20) tranquilization with acepromazine, fentanyl, or acepromazine associated with fentanyl or oral acepromazine

\begin{tabular}{ccccc}
\multirow{2}{*}{ Treatment } & \multicolumn{2}{c}{ HR $(b p m)$} & \multicolumn{2}{c}{ RR $(\mathrm{mpm})$} \\
\cline { 2 - 5 } & $\mathrm{M} 0$ & $\mathrm{M} 20$ & $\mathrm{M} 0$ & $\mathrm{M} 20$ \\
\hline CT & $107.6^{\mathrm{a}} \pm 14.2$ & $108.6^{\mathrm{aA}} \pm 43.2$ & $97.4^{\mathrm{a}} \pm 52.0$ & $153.8^{\mathrm{aA}} \pm 72.9$ \\
IAT & $110.4^{\mathrm{a}} \pm 24.8$ & $83.0^{\mathrm{bA}} \pm 12.1$ & $162.0^{\mathrm{a}} \pm 51.9$ & $125.6^{\mathrm{aA}} \pm 93.5$ \\
FT & $116.0^{\mathrm{a}} \pm 21.4$ & $88.7^{\mathrm{bA}} \pm 15.2$ & $128.6^{\mathrm{a}} \pm 53.8$ & $141.6^{\mathrm{aA}} \pm 42.07$ \\
AFT & $98.6^{\mathrm{a}} \pm 15.9$ & $81.15^{\mathrm{bA}} \pm 15.0$ & $115.6^{\mathrm{a}} \pm 58.7$ & $118.0^{\mathrm{aA}} \pm 49.79$ \\
OAT & $124.0^{\mathrm{a}} \pm 22.2$ & $71.4^{\mathrm{bA}} \pm 11.8$ & $141.4^{\mathrm{a}} \pm 57.1$ & $92.8^{\mathrm{aA}} \pm 62.53$ \\
\hline
\end{tabular}

Averages followed by the same capital letters in a column and lower case in a line do not differ statistically from each other by the Tukey test at the 5\% probability level. Subtitle: CT - control treatment; IAT - acepromazine treatment; FT - fentanyl treatment; AFT - acepromazine and fentanyl treatment; OAT - oral acepromazine treatment; M0 moment 0 (before drug administration); M20 - moment 20 (20 minutes after drug administration); bpm - beats per minute; $\mathrm{mpm}$ - movements per minute; $\mathrm{CV}$ - coefficient of variation. 
All RR values in M0 were above normal for the species due to the physiological tachypnea presented by the animals. Neither between treatments or between moments there was a significant difference in RR; however, a decrease in this parameter is reported in the literature using protocols with acepromazine (Gonçalves et $a l .$, 2009). The decrease in RR might cause a reduction of artefacts in the formation of the images, routinely caused by visualization of the pulmonary lobes.

Although the Simpson method was the most recommended for the evaluation of ejection fraction, it was not performed in this study due to the failure to obtain satisfactory images containing the entire luminal contour of the left ventricle, which would result in unreliable values. For a more complete evaluation of systolic function, Strain and Strain Rate methods could be used, however, these were not performed due to equipment limitations. Although the echocardiographic parameters used in this study are subjective in systolic and diastolic evaluation, they are routinely used for the echocardiographic evaluation of dogs and should be carefully interpreted in reassured animals.

\section{CONCLUSIONS}

Although the OAT confers a greater degree of animal reassurance than FT and IAT, this protocol causes a reduction in ventricular diameter, MAM, TAPSE and increase in E/A ratio, caused by the reduction of the preload consequent of the decreased SBP. The same changes in echocardiographic parameters are observed with IAT. The AFT decreases only the left ventricular diameter and MAM, with the same degree of animal reassurance from OAT. The FT does not cause changes in echocardiographic parameters. Decrease HR occurs in all protocols of tranquilization, which facilitate the echocardiographic examination. The findings of this study contribute to the correct interpretation of echocardiographic examinations when such tranquilizing protocols are used.

\section{ACKNOWLEDGEMENTS}

The authors thank Rancho Piorra where this study was carried out and FAPES (Espírito Santo Research Foundation) for Edina Alves dos Santos's Master Scholarship.

\section{REFERENCES}

ARENA, G.; BOTELHO, A.; EVARISTO, B. et al. Fenotiazínicos: usos, efeitos e toxicidade em animais de grande e pequeno porte. Rev. Cient. Elettron. Med. Vet., v.7, 7p., 2009.

BOON, J.A. (Ed.). Veterinary echocardiography. Iowa: Blackwell Publishing, 2011. 632p.

CARDOSO, H.M.; PADILHA, V.S.; TOCHETO, R. et al. Electrocardiographic, echocardiographic, and indirect blood pressure evaluation in dogs subjected to different sedation protocols. Ciênc. Rural, v.46, p.2043-2048, 2016.

CHETBOUL, V.; BUSSADORI, C.; MADRON, E. (Eds.). Clinical echocardiography of the dog and cat. Canada: Elsevier, 2015. 360p.

DELLA TORRE, P.K.; KIRBY, A.C.; CHURCH, D.B.; MALIK, R. Echocardiographic measurements in Greyhounds, Whippets and Italian Greyhounds - dogs with a similar conformation but different size. Aust. Vet. J., v.78, p.49-55, 2000.

GONÇALVES, R.C.; MASSONE, F.; MATSUBARA, L.M. Estudo comparativo entre a acepromazina, clorpromazina e levomepromazina em diferentes doses, através do exame bispectral, termo e pressoalgimetria, em cães. Semin. Ciênc. Agrár., v.30, p.921-930, 2009.

GRASSO, S.C.; KO, J.C.; WEIL, A.B. et al. Hemodynamic influence of acepromazine or dexmedetomidine premedication in isofluraneanesthetized dogs. J. Am. Vet. Med. Assoc., v.246, p.754-764, 2015.

GURNEY, M.; CRIPPS, P.; MOSING, M. Subcutaneous pre-anaesthetic medication with acepromazine-buprenorphine is effective as and less painful than the intramuscular route. J. Small Anim. Pract., v.50, p.474-477, 2009. 
HALL, J.A.; WATROUS, B.J. Effects of pharmaceuticals on radiographic appearance of selected examinations of the abdomen and thorax. Vet. Clin. N. Am. Small Anim. Pract., v.30, p.349-377, 2000.

HOFMEISTER, E.; CHANDLER, M.J.; READ, M.R. Effects of acepromazine, hydromorphone, or an acepromazine-hydromorphone combination on the degree of sedation in clinically normal dogs. J. Am. Vet. Med. Assoc., v.237, p.11551159, 2010.

KITTLESON, M.D.; KIENLE, R.D. (Eds.). Small animal cardiovascular medicine. Philadelphia: Mosby, 1998. 603p.

MUZZI, R.A.L.; MUZZI, L.A.L.; ARAÚJO, R.B.; LÁZARO, D.A. Doença crônica da valva mitral em cães: avaliação clínica funcional e mensuração ecocardiográfica da valva mitral. Arq. Bras. Med. Vet. Zootec., v.61, p.337-344, 2009.

PARIAUT, R.; SAELINGER, C.; STRICKLAND, K.N. et al. Tricuspid Annular Plane Systolic Excursion (TAPSE) in dogs: reference values and impact of pulmonary hypertension. J. Vet. Intern. Med., v.26, p.11481154, 2012.
RAM, R.; MICKELSEN, D.M.; THEODOROPOULOS, C.; BLAXALL, B.C. New approaches in small animal echocardiography: imaging the sounds of silence. Am. J. Physiol. Heart Circ. Physiol., v.301, p.1765-1780, 2011.

SAPONARO, V.; CROVACE, A.; DE MARZO, L. et al. Echocardiographic evaluation of the cardiovascular effects of medetomidine, acepromazine and their combination in healthy dogs. Res. Vet. Sci., v.95, p.687-692, 2013.

SCHOBER, K.E.; FUENTES, V.L. Mitral annulus motion as determined by M-mode echocardiography in normal dogs and dogs with cardiac disease. Vet. Radiol. Ultrasound, v.42, p.52-61, 2001

SPINOSA, H.S.; GÓRNIAK, S.L.; BERNADI, M.M. (Eds.). Farmacologia aplicada à medicina veterinária. Rio de Janeiro: Guanabara Koogan, 2011. 824p. 